\title{
HIKAJAT KISAH OELAT
}

Wormstekige stenen op Atjèh (en in Minangkabau?)

DOOR

H. T. DAMSTÉ.

$\mathrm{Na}$ de lange grote-vacantie, volgend op het binnenhalen van de rijstoogst, kost 't de Minangkabauer wel eens moeite, om weer aan het werk te gaan voor een volgende padi-productie-slag.

Waarschuwingen, dat 't mis kon gaan, zo hij niet tijdig zijn velden inundeerde en omploegde en plantklaar maakte, hoorde ik te Sidjoendjoeng in 1896/98 pareren met het bescheid: „Het wormpje in de steen schenkt Allah wel levensonderhoud, - hoe zou Hij dan ons, mensen, Zijn dienaren, laten verkommeren ? !' ${ }^{1}$ )

Ik verstond dat toen als een stuk universele wijsheid, geldend voor alle wormen en alle stenen en alle minangkabause gelovigen, in heden, toekomst en verleden, en dacht aan wormpjes in putten en groeven van het rotsoppervlak, en ook aan oelat's die de bakstenen deden verpulveren: zulke ,zieke" stenen, heetten die ook niet te zijn „dimakan oelès"?: door wormen of rupsen aangevreten? Al zulk alledaags gewormte, meende ik, had men op het oog.

In 1901 verhuisd naar Atjèh, las ik in Van Langen's „Handleiding voor de beoefening van de Atjehsche taal" op blz. 109 van de Oereuëng boeta njang peungeuïh até, d.i.: van de blinde die helder van geest was, zó helder, dat hij in het binnenste van een diamant een voor normale ogen onzichtbare worm kon signaleren.

Dat wormpje in die edele-steen deed mij toen nog niet terugdenken aan de minangkabause steen-wormen.

In 1912 te Idi (Atjèh's Oostkust) vertelde mij de radja van Bagòs en Boegéng: Teukoe Béntara Moeda, van de blinde Aphé, die ook

1) De Atjèher uit zijn vertrouwen dat hem niets zal ontbreken, een tikje rauwer: „Geuplah babah geubri raseuki” zegt hij, d.i. „Ik ben geschapen met een spleet, - dan zorgt de Heer wel dat ik eet!" 
in een diamant de aanwezigheid van een worm vaststelde, - van een oelat met spriet paardengras in de bek nog wel!

Ik zei 't verder in „de Indische Gids" van 1916 (blz. 760 -765), maar had ook toen nog geen suspicie op mogelijke betrekkingen tussen de minangkabause en de atjèhse wormen.

Maar nu ben ik vol achterdocht: Onlangs ontdekte ik een kleine Hikajat Kisah Oelat, achter in een dik handschrift van gemengde inhoud, mij anno 1925 uit Atjèh toegezonden, om de er in voorkomende zeer uitvoerige verhandeling over de heilige oorlog. Het beginblad van dat Wormendicht ontbreekt, zodat we van de inleiding een of twee bladzijden moeten missen; maar er resteren er nog twaalf, met totaal 213 versregels; en na hun lectuur vraag ik mij af : Zou ik de minangkabause worm indertijd niet hebben misverstaan en onderschat? Zouden alle vroeger ter Westkust en later op Atjèh tegengekomen wormen niet even zo vele verschijningsvormen zijn van één oer-worm van nog nader vast te stellen huize, welke, volgens gezegde hikajat, tot in de dagen van Moehammad, verbleef binnen een juweel, waar hem door Allah's goedertierenheid voedsel werd verstrekt, honderd eeuwen lang, tot op de dag toen de profeet de steen brak en de worm, rood als bloed, de vrijheid kreeg?

Van die vrijheid - zo lezen we - maakte hij gebruik om de mohammedaanse geloofsbelijdenis uit te spreken, het volk van Perzië aan te manen zich tot de islām te bekeren, heel veel goeds te zeggen van de profeet Moehammad, en, door deze daarnaar gevraagd, wat te vertellen van het séjour in het juweel: de lofliederen daar gezongen en de gevarieerde tafel dien men er kreeg opgediend.

Zou van het wonder van die spijziging, de eeuwen door, van dat wormpje in zijn diamanten cel de Minangkabauer hebben geweten? vraag ik mij thans af. Zou hij dàt éne speciale wormpje hebben bedoeld? en uit deszelfs goede ervaringen het vertrouwen hebben geput, dat 't wel los zou lopen met de voedsel-positie, óók wanneer hij zich niet zo bijster hard inspande om die goed op peil te houden?...

Onze bronnen van schriftelijke informatie zijn dus drie in getal: A. de Hikajat oereuëng boeta peungeüh até in Van Langen's „Handleiding voor de beoefening der Atjehsche taal” van 1889. Dit

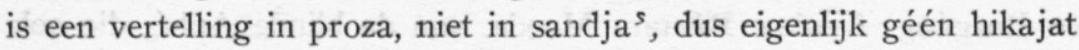
naar de verklaring die Snouck Hurgronje in „De Atjèhers” (dl II p. 79) geeft van het begrip ,hikajat" zo als de Atjèhers dat voelen. B. het in de Hikajat Peutawi door Teukoe Béntara Moeda, radja 
van Bagòs en Boegéng (Idi), gerijmelde verhaal van de blinde Aphé, vertaald weergegeven in ,De Indische Gids” van $1916 \mathrm{blz}$. 760-765.

C. de Hikajat Kisah Oelat, welke het slotstuk vormt van een in 1924 te Poetjō ${ }^{s}$ Aloeë Doea in Simpang Oelim door een Mantri Politie bij Habib Hoesein bin Ali al-Atas alias Habib Kramat in beslag genomen 8 centimeter dik handschrift, dat mij in 1925 door Atjèh's gouverneur Hens werd toegezonden.

A en B geven staaltjes van helderziendheid van een blinde, die het wezen van stenen, paarden en mensen weet te onderkennen. In $\mathrm{C}$ is het beschouwingsobject enkel een steen, en de ziener die in de steen de worm signaleert is hier geen blinde maar niemand minder dan de profeet Moehammad en de vertelling wordt ons opgediend als een gewijde overlevering. Van de voeding van de worm in de steen wordt in A niet gewaagd; in B is er enkel een aanwijzing voor: de worm heeft een grasje in de bek; maar in C wordt zij uitdrukkelijk vermeld en God was 't die ze bezorgde.

Merkwaardig in $\mathrm{C}$ is de groepering: Moehammad in het midden en om hem heen de acht vrienden: Aboe Bakr, Oemar, Oethman, Ali enz., die allen front maken naar de profeet, als fonkelende sterren die de volle maan omkransen.

Die opstelling herinnert aan het door Çivaieten en Buddhisten in hun mystieke diagrammen veel gebezigde patroon van de achtbladige lotus, met op de bladen (windstreken soms) geplaatste aspecten van een centrale hoofdfiguur in het lotushart. Maar meer direct lijkt de aanverwantschap met het negenvoudige zegel, ,tjab sikoereuëng”, van de Atjèhse soeltan's, dat, gelijk Rouffaer heeft aangetoond, een navolging was van het grootzegel van Hindostan's grootmogol, en van bij diens inhuldiging gebezigde strooimunten. Zijn zulke voorstellingen van de vorst, te midden van een aantal voorgangers, ook in Perzië bekend geweest? Men zou 't zo menen, na lezing van het bericht, dat ik indertijd noteerde uit „Die Woche” van 13 Maart 1926: „Ein Krönungsandenken. Anlässlich der Thronbesteigung des neuen Schah von Persien Riza Khan, wurde eine Erinnerungskarte herausgebracht, die den neuen Herrscher im Kreise seiner Vorgänger zeigt".

Resumeren we A en B, en volge dan C: de „Hikajat Kisah Oelat” te voeten uit met vertaling.

Volgens de vertelling van Van Langen lijft de vorst de blindeman 
in bij de verzameling curiositeiten, zo als vorsten die er op na plegen te houden. Maar de helderziende is een curiosum waar de vorst pleizier van heeft! Hij ontraadt zijn heer de koop van een prachtig mooi hengstveulen: het zou buffelmanieren hebben, als gevolg van het verkeer dat de merrie waaruit het geboren werd tijdens haar dracht had gehad met karbouwen. Daardoor vertoonde 't nu de hebbelijkheid, als men 't wilde bestijgen, dat 't op de grond ging liggen. De proef wordt genomen, en 't blijkt waar te zijn; dus is de jonge hengst zo veel waard als zijn mooie huid waard is, maar ook niets meer! De koop springt af.

Een volgend maal wil de vorst een diamant kopen, maar de blinde waarschuwt: de steen is de prijs niet waard, want er zit een worm in! De blinde blijkt al weer goed gezien te hebben. En zo bewijst hij de vorst méér grote diensten. Maar deze toont zich niet dankbaar: hij gaat voort de blinde op het oude rantsoen water en brood: één klapperdop water en een half brood, te huisvesten in een miserabel vuil hok.

Op een nacht gaat de vorst hem daar opzoeken. De blinde moet hem betasten, want Hoogheidje wil weten waar hij aan toe en wat hij waard is. De blinde probeert er zich van af te maken, maar gedwongen doet hij ten slotte uitspraak: Onnodig is 't de vorst aan te raken, zegt hij; enkel al diens houding tegenover hèm toont aan, dat de vorst geen zoon is van zijn nominale vader en voorganger.

De vorst ondervraagt zijn moeder, en zij bekent: Ze hadden eris gepicknickt aan het zeestrand, wijlen de koning, zij de koningin, en vele hovelingen, en de stoet keerde terug paleiswaarts, de vorstin gezeten op de schouder van een abessinische slaaf, toen er kwaad weer kwam opzetten. De regen begon te vallen en de vorstin zei een plek te zoeken waar men kon schuilen. Een paardenstal werd gevonden, en daar gingen de koningin en haar drager binnen, maar de volgelingen bleven buiten. En toen gebeurde ' $t$ in de kleine ruimte van de paardenstal, dat de koningin ging letten op Si Meureudjan, - zo heette de slaaf die haar gedragen had. Zij ontdekte het mandier in de Abeusi (Abessiniër), en alles verliep naar Godes voorbeschikking. De koningin werd zwanger, en uit die zwangerschap werd geboren hij die nu koning was; maar diens natuurlijke vader, Si Meureudjan, was lang gestorven!

De vorst vraagt de blinde de zaak geheim te houden. Hij bezorgt hem een vrouw, geeft hem van allerlei, maar ten leste, toch bang voor publiciteit en schande, neemt hij vergif in en sterft, en een 
ander vorst volgt hem op in de regering des lands.

\section{B}

In de Hikajat Peutawi in "De Indische Gids” heet de blindeman Aphé. Hij ziet ook erg helder en heeft speciaal kijk op stenen, paarden, vrouwen en op de echtheid of onechtheid van der mensen geboorte. Hij trekt de aandacht van de vorst, zodat, wanneer deze in de verleiding komt een buitengewoon grote ,malakat" (wondersteen) te kopen voor tien baren gouds, hij zich de blinde Aphé herinnert.

Aphé, gehaald, oordeelt, dat wanneer er niets aan mankeerde, de steen meer dan het dubbele waard zou zijn; maar er mankeert wèl iets aan: in de steen zit een worm, en in de bek houdt deze een spriet „naleuëng goeda" of paardengras.

De verkoper gelooft dat niet. Geen cent zou hij willen ontvangen, als er aan zijn steen ook maar iets mankeerde! De steen wordt gespleten, en de blinde blijkt goed gezien te hebben. 's Avonds wordt hem van wege de vorst een halve apam-koek thuis bezorgd bij wijze van honorarium. Aphé besluit hieruit, dat de vorst niet van zuiveren vorstelijken bloede kan zijn.

Later is 't over een span paarden dat de vorst Aphé's oordeel wil horen. Een slaaf komt hem halen, maar Aphé weigert mee te gaan: die vorst, zo'n bastaard, neen, daar wil hij niets meer mee te maken hebben! Met die boodschap komt de slaaf bij de vorst; maar deze stuurt hem terug: hij móét Aphé brengen, desnoods met geweld. Aphé komt, en krijgt te oordelen over de paarden. Prachtige paarden! zegt Aphé, en als er niets aan mankeerde, mocht de prijs het dubbele zijn van hetgeen de paardenhandelaar ervoor vraagt. Wat zou er aan mankeren? vraagt de handelaar; als er iets aan mankeert wil ik geen betaling hebben! dan stap ik zo, zonder paarden en zonder geld, naar huis! Aphé vertelt nu, dat drie dagen na de geboorte van de veulens het moederpaard gestorven was. Sinds waren de veulens gezoogd door een karbouw en daardoor hebben zij nu buffelmanieren. De proef wordt genomen en jawel! als de paarden zich warm hebben gelopen, springen ze pardoes in de rivier! De paardenhandelaar druipt af, met achterlating van zijn veulens en zonder daar een kwartje betaling voor te hebben ontvangen! Aphé gaat ook naar huis en krijgt voortaan trouw iedere ochtend en iedere avond telkens een halve apam-koek. 
Weer komt een handelaar de vorst iets moois aanbieden, ditmaal een vrouw, geprijsd op 5000 daalders. De prijs is hoog, maar voor dit geval niet tè hoog meent de vorst; maar - een kleine moeite Aphé even te horen. En Aphé oordeelt: Was de vrouw zonder gebreken, zij zou meer dan dubbel zoveel mogen kosten!

Wat gebrek zou zij hebben? vraagt de handelaar. Ziet, zij vertoont de zeven schoonheden! Heeft zij enig gebrek, dan laat ik haar u om niet!

$\mathrm{Nu}$ onthult Aphé, dat, toen de vrouw drie dagen oud was, zij haar moeder verloor. $Z_{\mathrm{ij}}$ werd toen verder gezoogd door een lichtekooi, en die was haar ook later blijven verzorgen. Maar daarmee was meteen de toekomst van het meisje ongunstig bepaald: dit was nu voorbeschikt een veile deern te worden.

De jonge vrouw bevestigt Aphé's verklaringen, en de handelaar gaat heen, met veel zorgen en zonder geld, en met achterlating van de schone.

Maar had onlangs Aphé geen lelijke dingen gezegd over 's vorsten afkomst?

Daarvoor verdient hij te worden gedood! Dus trekt de vorst zijn zwaard, en sommeert Aphé nu eens alles van die afkomst te vertellen. Aphé antwoordt, dat de vorst daar beter naar kan informeren bij zijn mama. En die moeder, als haar het mes letterlijk op de keel wordt gezet, onthult, dat haar huwelijk niet zo gelukkig is geweest. $\mathrm{Na}$ een halve nacht bij haar te hebben doorgebracht, was de vorstelijke gemaal heengegaan, om nooit meer terug te komen. Maar een sirih-zak had hij achtergelaten, en om die op te halen zond hij een bileuë (bilāl) die een adonis was. Met die bilāl had de koningin toen vriendschap gesloten, en dat had gevolgen gehad: zij was zwanger geworden en had een zoon gekregen: de zoon die nu vorst is en naar zijn afkomst vraagt. Verklaard is nu ook, waarom Aphé steeds op halve apam-koeken wordt onthaald: 't behoort tot de taak des bilāl's om bij zekere festiviteiten apam-koeken te serveren, na die te hebben doorgesneden.

De vorst verzoekt Aphé de zaak geheim te houden, en zij verkeren voortaan als broeders: Aphé de oudere, de radja de jongere.

$\mathrm{Nu}$ de derde versie: de „Hikajat Kisah Oelat”, te voeten uit en met vertaling als beloofd. 
Te voeten uit, dat zal gaan; maar aan het schedeldak moet de sier van de kōteubah blijven ontbreken.

We zeiden 't reeds : het handschrift is niet geheel gaaf : het beginblad mankeert. Maar het begin van een hikajat is steeds een kōteubah (preek-vooraf, proloog, inleiding) en gewoonlijk is dat voorwerk niet onmisbaar voor het verstand van het eigenlijke verhaal.

Lezers die haast hebben, zullen het verlies als winst weten te appreciëren. 


\section{HIKAJAT KISAH OELAT}

Tamsé nabi ban mata oeròë - peungeuih nanggròë ban di dōnja

Lingka nabi sahbat lapan -- ban boeleuën trang poedòë ra 'na

Nabi Moehamat lang-goemilang — sang boeleuën trang teungòh [peureunama

Ban peureunama meung lōn tamsé - leubèh tjit teuma meugeuganda

Sahbat lapan tamsé bintang — hadab djoendjōngan ban sineuna

Sahbat lapan han tatoesòë — ngò lōn hareutòë teubileuëng sa

Phōn lōn peugah Aboe Baka - sahbat njang toeha nabi meulia Keudoea aneu' Katabi -- oebas nabi sangat meulia

Keulhèë Oseuman aneus Aphan - keupeuët Toean Ali Mòreutala

10 Bandoem sahbat meulintō nabi - Awōïh ngòn Doebi nam dròë [njang ka

Keutoedjōh Sa ét sahbat nabi - Sajman Parisi sidròë nama Abéh lōn peugah ka ban lapan - bandoem toean that meulia Nabi Moehamat noe al-alimin - djeumala al-'alam keumala dōnja

Doemna sahbat lapan doeës meulingka - nabi teuma teungòhnja Teuma teuka oereuëng sidròë — oereuëng lakòë moeda balia Njankeu sahbat Aboe Djahé - djidjas ${ }^{s}$ landja ba ${ }^{s}$ sòjdina 'Oh trōih keunan oebas nabi - saleuëm geubri hōreumat meulia Asalamoe 'alòjkōm ja rasoelōlah — sidjahtra Alah ateuëh gata Teuma neudjaweuëb saleuëm djeunòë — 'alā man ittaba a '1-hudã

20 Teuma neutanjòng oelé nabi - peuë djihadjat keunòë teuka Teuma djiseus ōt pantaih-pantaïh — kamòë langkah tjit ba ${ }^{s}$ gata Djakalèë tadjas $^{s}$ ja Moehamat - sadjan kamòë djeunòë geuba $\mathrm{Tadja}^{5}$ kalòn doem piasan - peureumanjèn indah roepa Oebas $^{s}$ teumpat Aboe Djahé - patōng 'adi sit that meulia Badandjih sangat indah - meuih meutatah moepeureumata Patōng djipeudoeës ateuëh teurapan - poedòë intan blèt-blòt tjahja 


\section{WORM GEDICHT}

De profeet is als de zon, waardoor 't licht is in de landen van [geheel de wereld.

Om de profeet heen zijn de acht vrienden, gelijk de volle maan en [gruis van diamant.

De profeet Muhammad glanst als de volle maan op het hoogtepunt [harer volheid.

Met vollemaneglans wil ik zijn schittering vergelijken, maar die [dan nog weer verveelvoudigd.

De acht vrienden zijn als sterren, allen eerbiedig front makend [naar de vereerde.

Kent ge de acht vrienden niet? Luistert dat ik hen u noeme, een [voor een :

Eerst noem ik $A b u B a k r$, de oudste vriend van de edele profeet. In de tweede plaats Umar, zoon van al-Khattāb, die de profeet [zeer toegewijd was.

In de derde plaats Uthmān, zoon van Affān; in de vierde: heer $[A l i$, in wie God welbehagen heeft.

10 De vrienden omstuwden de profeet als begeleidden zij een bruidegom.

[Aws en al-Zubair brengen het cijfer op zes. Nommer zeven was $S a^{\mathrm{c}} \bar{\imath} d$, en dan was er nog één : Salmān Färisī. Alle acht heb ik hiermee genoemd. Allen, heren, waren zij zeer edel! De profeet Muhammad is het licht der werelden, het hoofd, het [juweel van deze aarde.

Alle acht vrienden zaten in het ronde, en de profeet zat in hun midden. Toen kwam er iemand, een welgevormde jongeman.

Hij was een gezel van $A b u D j a h l$, en begaf zich meteen tot onze heer. Gekomen tot voor de profeet, bracht hij zijn eerbiedige groet. „Heil over u o godsgezant! de vrede Allah's zij over U!” De profeet antwoordde: „Vrede zij over wie de leiding volgt!”

20 En vroeg: wat hij wenste, dat hij zo kwam.

Vlot kwam het antwoord: „We zijn zo maar eens naar u toe gestapt. Wilt ge mee gaan Muhammad,

Dan gaan we kijken feesten en schone spelen

In de stede van $A b u$ D jahl. Daar staat een schitterend godenbeeld.

De romp is zeer fraai: goud, ingelegd met edelstenen.

Het beeld staat op een wierookvat en het diamantgruis flonkert [en flikkert. 
Tirè rawa indah-indah - di $^{s}$ ateuëh khimah djibōh soetra

Oereuëng disinan meuleulas ${ }^{5}$ in - djikhōdeumat doem patōng 'aza

Nabi neungò haba moemeunan - neubeudòï jōh njan sigra-sigra

30 Nabi djiba jōh masa njan — sahbat lapan sadjan seureuta Hingga trōïh rab $\mathrm{ba}^{s}$ khimah - rasoelōlah njang that meulia Laloe djidjas ${ }^{s}$ oereuëng sidròë - oereuëng lakòë oeba ${ }^{s}$ radja Saré trōïh bas Aboe Djahé - djidèëlat lé jōh njan djipoemeulia Dèèlat teugajō tjah alam - Moehamat amin keunòë teuka .

$\operatorname{Djidja}^{\mathrm{e}}$ kalòn doem piasan - sahbat sadjan doem seureuta

${ }^{\circ} \mathrm{Oh}$ djideungò haba meunan - djipeus ingat jōh njan sigra-sigra Kadeungò hé kawōm Koeréh - ngò beu habéh ban sineuna Moehamat 'òh trōih keunòë djidja ${ }^{s}$ - kapeutamòng bas khimah

Bès meulia pi meung sabòh - bès sòë beudòïh doemna gata

40 Bès kahadab ba ${ }^{\text {s }}$ Moehamat - kapeulikōt doemkeu rata

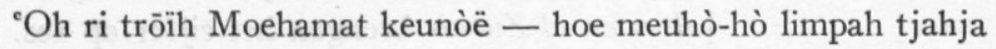
Ala Ta a ala boeka hịjjāb - ateuëh moeka Moehamat nabi meulia Tjahja Moehamat lang-goemilang — trōih meureuntang hò adara Tamsé beuneung radja timòh - meunan peunòh tjahja moeka Alah bri hibat bas Moehamat - kaphé lasnat abéh geumpa Até moebhō̄s-bhōs atōt meutat - sabab hibat nabi meulia Misé oeròë teungòh beukah - meunan limpah gilang tjahja Hana sidròë pi meuteuntang - han djeuët djipandang seupōt mata Misé tapandang $b a^{s}$ mata oeròe - meunankeu pròë ba ${ }^{s}$ oepama 50 Sabab hibat Moehamat sidròe — $\mathrm{ra}^{s}$ jat meukatòë beudòïh doemna 
Daar hangen fraaie gordijnen uit $R a u$ en boven de tent is een [uitspansel van zijde.

Drommen mensen verdringen zich daar om het beeld te huldigen [en te dienen."

Horend dusdanig bericht, stond de profeet op.

30 Alsdan geleidden ze de profeet, en bij hem waren de acht vrienden. Toen de zeer edele godsgezant de tent reeds dicht was genaderd, Begaf zich een man naar de radja.

Gekomen bij $A b u$ Djahl, bracht hij hem hulde en bewees hem eer: „Majesteit die lang moge leven, Heer van de wereld! Muhammad [is gekomen.

Hij komt de bezienswaardigheden kijken en zijn gezellen heeft [hij bij zich."

Horende zulke tijding, waarschuwde $A b u$ Djahl haastig:

„Gij Kuraisjieten moet allemaal eens goed luisteren!

Als Muhammad hier zal zijn gekomen, brengt ge hem in de statie-tent,

Maar laat niemand hem énige eer bewijzen! Niemand mag voor

[hem opstaan!

40 Geen frontmakerij naar Muhammad! Allemaal moeten je hem de [rug toekeren!"

Toen Muhammad nader kwam, drong zijn glans in alle richtingen [door, alles badend in licht.

Want Allah de Verhevene nam de sluiering weg van voor het [aangezicht van de edele profeet.

Van de lichtglans rond Muhammad schoten stralen uit, recht ten [hemel.

Als van een regenboog, zo vol was het lichten van zijn gelaat. Allah verleende Muhammad een ontzagwekkend voorkomen, zodat [de vervloekte ongelovigen stonden te trillen. De harten bonsden, de gewrichten beefden, - zo'n indruk maakte [de edele profeet.

't Was of de zon bezig was op te gaan, zo werd alles overgoten [door zijn lichtglans.

En niemand keek in zijn richting, want men kon niet naar hem op [zien, of men werd verblind:

't Was net alsof men in de zon keek! zo leek 't.

50 Door de indruk die Muhammad maakte, stond de mensenmassa [als één man op. 
Seureuta djidjoendjōng doem $\mathrm{ba}^{s}$ nabi - oebas gaki djeuëb koepala Ladoem djiseumah rōh di teu ōt - seureuta teumakōt beureukoepala

Teuma djibeudòih di Aboe Djahé - djimat di djaròë nabi meulia Aboe Djahé mat djaròë nabi — djipeudoeës lé ateuëh keuta Teuma djidoeës doemdjih sadjan - di hadapan nabi meulia Aboe Djahé doeës di nab nabi - ban moerib doeës di nab sòjdina Misé oelōn doeë ${ }^{s}$ di nab pò - meunan lakoe ba $^{s}$ oepama $\mathrm{Na}$ sidjamòng doeës disinan - tangò tèëlan koetjalitra

Teuma djimarit Aboe Djahé - jōh njan djisoeseuë bas sòjdina 60 Tangò oelōn hé Moehamat - koetanjòng sapeuë oeba ${ }^{s}$ gata Meung djeuët tapeugah tanjòngkoe njòë - iman kamòë njan keu

Koepatéh gata njò bit nabi - han koemoengki Toehan keu gata

Koepatéh gata rasoelōlah - meung djeuët tapeugah èleumèë rasia

Rasoej djaweuëb jōh masa njan — tatanjòng peuë lèt kheundas

Seureuta neukheun éntja Alah - sit geupeugah doem peukara Teuma djikheun lé Aboe Djahé - djimeusoeseuë ngòon sòjdina Hé Moehamat beukit kathèë - lam badjèë kèë peuë salèh na Beukit katoepeuë lam badjèë - koepatéh mèë djeunòë gata Lam djaròë gata moemaso $\bar{c}^{\circ}$ éseulam - agama pi teuma misé di gata

70 Nabi teudeungò haba moemeunan - teupiké jōh njan sikoetika Hana neudjaweuëb oelé nabi - neuprèh Djibrasé gòh lòm teuka

Peureuman Toehan ba ${ }^{5}$ Djibra ${ }^{s}$ é - neujoeë trōn lé oe lam dōnja Hé Djibrasé kangò koepeugah — djas lèh trōn kah djeunòë oe dōnja

$\mathrm{Dja}^{\mathrm{s}}$ keu katrōn djeunòë oe boemòë $-\mathrm{kadja}^{\mathrm{e}}$ joeë ba ${ }^{\mathrm{e}}$ mòseutapa Kajoeë djaweuëb kaphé las nat - kajoeë ingat doem rasia

Djibrasé ba peureuman Toehan - jōh njan neutrōn oe lam dōnja Djibrasé dòng di hadapan - peureuman Toehan neutjalitra

Ja Moehamat tangò koepeugah - saleuëm Alah njan keu gata 
Alle hoofden brachten de profeet hulde aan diens voeten.

Sommigen brachten hem de kniekus, en angstig stelden zij zich

[onder hem, als onder hun hoofd.

Abu D jahl stond op, vatte de hand van de edele profeet

En nodigde hem plaats te nemen op een zetel,

En allen zetten zich daarop neer voor de edele profeet.

Abu Djahl zat vóór de nabi als een discipel, zo zat hij voor onze heer;

Als een slaaf zit voor zijn meester, dáármee liet 't zich vergelijken.

Een ogenblik had men zo gezeten, toen - luistert makkers, ik zal

['t u vertellen.

$A b u$ Djahl sprak toen vragend aan onze heer :

60 „Hoor mij aan o Muhammad, ik heb $\mathrm{u}$ iets te vragen.

Zo ge kunt beantwoorden mijn vraag, zal ons geloof zijn in u.

Ik geloof dan dat gij inderdaad zijt een profeet, en niet loochen [ik God meer tegenover u.

Ik neem dan aan dat gij zijt de godsgezant, zo ge kunt zeggen [(mijn) geheime wetenschap."

De profeet antwoordde toen: „Vraag maar vrij wat je lust!”

Maar aan al wat hij zei voegde hij toe de woorden ,zoo God 't wil!” $A b u$ Djahl sprak toen, vragende aan onze heer:

„He Muhammad, als ge kunt zeggen wat er wel zit in mijn baadje, Dan dien ik u te vertrouwen.

In uw handen gaan wij dan over tot de islām en onze godsdienst [zal zijn als de uwe."

$70 \mathrm{Op}_{\mathrm{p}}$ het horen van dusdanige taal dacht de profeet een ogenblik na, Maar de nabi antwoordde nog niet: hij wachtte op Gabriël die [nog niet was gekomen.

God gelastte Gabriël neer te dalen op aarde : „He Gabriël, hoor eens wat ik je te zeggen heb! Ga gij nu [neerdalen op aarde!

Daal gij nu neer op de wereld, en ga boodschappen de aangebedene, Zeg hem die vervloekte ongelovige van antwoord te dienen! laat

[hij zich herinneren al het verborgene!" Gabriël nam in zich op het woord Gods en daalde af naar de wereld. Hij ging staan vóór (Muhammad) en wat God gezegd had bracht [hij over:

„O Muhammad, luister naar wat ik heb meê te delen: Godes heil [is over U. 
Tanjòng kaphé lasnatōlah — neujoeë tapeugah sigra-sigra

80 Lam djaròë badjèë na sabòh intan — djròh hana ban that meutjahja

$\mathrm{Ba}^{\text {s }}$ oereuëng lakòë nanggròë $\mathrm{Njaman} \mathrm{-} \mathrm{djiblòë} \mathrm{disinan} \mathrm{oeròë}$ [seulasa

Djiblòë doeablaïh ribèë dina - doemnankeu beuna takheun hareuga

Di teungòh intan sabòh oelat - mirah pi that lagèë dara

$\mathrm{Ba}^{5}$ babah oelat pi meuteuntèë - djeunèh ōn kajèë idjō roepa

Beukit han djipatéh ban takheun - tajoeë pròh intan oelé gata Nameung dji ${ }^{s}$ eu dalam intan - keukajasan Alah Ta ala

Lheuëh Djibrasé peuroenòë nabi - neudjaweuëb lé sigra-sigra Lam djaròë badjèë na sabòh intan — djròh pi han ban indah roepa $\mathrm{Ba}^{s}$ oereuëng lakòë nanggròë $\mathrm{Njaman}$ - tablòë disinan oeròë seulasa

90 Doeablaih ribèè dina tabri - doemnan hasé $b a^{s}$ hareuga

Di teungòh intan oelat mirah — roepa indah lagèë dara Di babah oelat ōn kajèë idjō — ras jat tahe djingò sabda

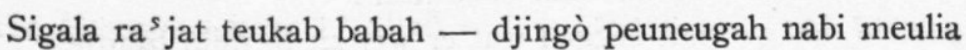

Aboe Djahé pi teutjeungang - hireuën mantòng neuseu mata (?)

Aboe Djahé lòm djisoedi - oebas nabi djikira poera Pakri tathèë ja Moehamat - sòë bri ingat nibas gata Tangò pi tan takalòn han — bit njò meunan salèh poera

Jōh njan neudjaweuëb oelé rasoej - Toehankoe sidròë bri rasia

Toehan njang peudjeuët langèt ngòn boemòë — njang peudjeuët [geutanjòë doem barang na 100 Ateuëh langèt neupeudjeuët araï — ateuëh boemòë neupeudjeuët [radja

Keuneubah di las ōt doem njang indah — manikam ngòn meutiara Aboe Djahé han djipatéh — djipeudjajéh djikheun poera 
Op de vragen van die ongelovige, op wie Gods vloek rust, gelast

[God vlug kond te doen,

80 Dat er in de mouw van zijn jas een diamant zit, buitengewoon

[schoon en sterk van schittering.

Van een man uit Jemen is die gekocht, verleden Dinsdag,

Voor twaalfduizend dinar. Dàt - moet ge zeggen - was in

[waarheid de prijs.

Maar in het hart van de steen bevindt zich een worm, hel rood [als bloed,

En in de bek van de worm zit gewis een boomblaadje, groen van kleur.

Gelooft hij niet wat ge zegt, laat dan de steen verbrijzelen,

Opdat hij ervare aan die diamant het alvermogen van Allah de

[Verhevene!"

Nadat Gabriël de profeet onderricht had, antwoordde deze snel:

„In de jasmouw zit een diamant, buitengewoon schoon en fraai!

Van een man uit Jemen kocht ge die verleden Dinsdag.

90 Twaalfduizend dinar gaaft ge er voor; dàt was de prijs die werd [afgemaakt.

Maar in het hart van de steen zit een rode worm, schoon als bloed, En in de bek van de worm steekt een groen boomblaadje." Het

[volk stond versteld toen 't dat zeggen hoorde.

De ras ${ }^{s}$ jat's, vernemend de mededeling van de edele profeet, beten

[zich in de mond.

Ook $A b u$ Djahl toonde zich zeer verbaasd. Enkel verwondering [sprak uit zijn blik (?).

$A b u$ D jahl vroeg verder, denkend dat de profeet wat geblageerd had:

„Hoe weet ge dat Muhammad? wie bracht u op die gedachte?

Ge hebt niets gezien noch gehoord! Ge maakt toch zeker maar

['n grapje?!'

Toen antwoordde de godsgezant: .,De Here-mijn alleen verklaarde

[mij wat geheim was,

De Heer die schiep hemel en aarde en ons allen.

100 Boven de hemel schiep Hij Zijn troon, en over de aarde stelde Hij [de vorst,

En de geborgenheden in zee bestonden in allemaal schone zaken:

[juwelen en parelen."

Maar Abu Djahl geloofde niet: hij bagatelliseerde de zaak; praatjes [voor de vaak waren 't! zei hij. 
Teuma beudòì Aboe Baka - toeanteu Oema sadjan seureuta Beudòih Oseuman deungòn $\mathrm{Ali}$ - ka neukheun lé sigra-sigra Adat han tapatéh rasoelōlah - tapròh boe beukaïh intan gata Pakri koepròh intan gòb njòë - moeblòë di kamòë le that hareuga

Hareuga tablòë kamòë gantòë — beukeusit tan ban tjalitra Barangkadoem hareuga tablòë - siplōh katòë kamòë peuna Adat han séb siplōh katòë - bah meugantòë siplōh bahra 110 Nameung djikalòn doemna ra ${ }^{s}$ jat - koeasa halarat Alah $\mathrm{Ta}^{\mathrm{e}}$ ala

Dami djideungò haba moemeunan — pròhkeu kaman oelé gata

Kakeu djidjōs ${ }^{5}$ oeba $^{e}$ nabi - neusambōt lé sigra-sigra

Seureuta neubatja ngòn béseumélah - intan pi beukah ka djeuët [doea

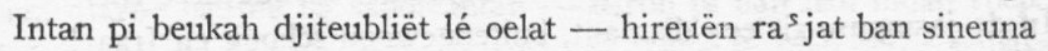

Djikalòn oelat pi bit mirah - ban peuneugah han meutoeka

Jōh njan oelat djis oetjab tjahdat - tahe $\mathrm{ra}^{s}$ jat meuleulas sa

Atjeuhadoesan La élaha élalah — waheudahoe lā tjarīka lahoe Wa atjeuhadoes anna moehamadan 'abeudoehoe wa rasoelahoe $\mathrm{Ma}^{s}$ na djinòë lōn tjalitra - jōh njan oelat $\mathrm{dji}^{s} \mathrm{e}^{s} \mathrm{sa}^{s} \mathrm{si}$

120 Deungò saré doemna gata $-\mathrm{koe}^{s} \mathrm{e}^{s} \mathrm{sa}^{s} \mathrm{si}$ hana Toehan maléngkan

Han sa keu Toehan sibagòë - meuhasoetji Alah Ta ala [Alah Ta'ala

$\mathrm{Koe}^{s} \mathrm{e}^{s} \mathrm{sa}^{s}$ si Moehamat amin - hamba Toehan ngòn rasoelōlah

Soerōh Toehan doem sikeulian - djén ngòn insan abéh doemna Kaphé deungò tjahdat oelat - tahe $\mathrm{ra}^{s}$ jat meuleula ${ }^{5} \mathrm{sa}$

Ngòn soeara pi raja that — djideungò ras jat doem barangna

Lòmpi djikheun oelé oelat - oeba ${ }^{s} \mathrm{ra}^{s}$ jat ban sineuna Kadeungò hé kawōm Pareusi - ba ${ }^{s}$ patéh nabi meulia Sòë han patéh nabi Moehamat - kaphé las nat asòë nòraka

Sabét keu djih adeuëb njang peudéh — djan kiamat pagé njata 
Abu Bakr stond op, en met hem onze heer Umar;

En op stonden ook Uthmān en $A l i$; en snel zeiden zij:

„Zo ge de godsgezant niet gelooft, sla dan stuk je diamant!"

„Hoe zou ik stuk slaan dezer lieden diamant, die wij kochten tot

[zeer hoge prijs?!"

„Uw koopprijs vergoeden we u, als 't niet uitkomt naar wat gezegd is!

Hoeveel ge er ook voor betaald hebt, — tien kati goud leggen we neer!

En is tien kati nog niet genoeg, laten we $\mathrm{u}$ dan tien baren vergoeden!

110 Als de ra ${ }^{s}$ jat's de macht maar zien van de alvermogende

[verheven God!"

Horend dusdanige woorden (zei $A b u$ Djahl): „Sla gij de steen [dan maar stuk!"

En hij gaf die aan de profeet. Deze nam hem snel aan

En, terwijl hij zei „In Gods naam!”, brak hij de steen in twee.

Toen nu stuk was de steen, kwam daar, tot verbazing der ras jat's,

[een worm uit.

Zij zagen: de worm was inderdaad rood! Met het zeggen klopte ['t precies!

De worm sprak toen de geloofsbelijdenis uit, en de menigte ra ${ }^{\text {s }}$ jat's [stond verbluft :

Asjahadu'san Lā ilāha 'llah waḥdahu lā sjarīka lahu wa asjahadus an anna muhamadan 'abduhu wa rasulahu

De zin dezer woorden vertel ik nu: De worm trad toen op als getuige:

120 „Hoort allen!” (zei hij) ,ik getuig, dat er geen God is dan Allah [de Verhevene.

Niets en niemand kan God evenaarden. Opperrein is God de [Verhevene!

Voorts getuig ik, dat Muhammad Amin des Heren dienaar en [Godes gezant is.

De Heer gezegt allen: geesten, mensen, - allemaal!"

Horend wormpjes belijdenis, stonden de talloze ongelovigen stom [verbaasd.

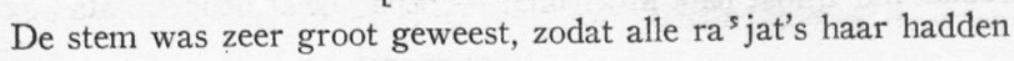
[gehoord.

Nòg sprak de worm tot het volk te gader:

„Hoort gij o Perzen! Wilt geloven in de edele profeet!

Wie niet gelooft in de profeet Muhammad is een vloekwaardige [ongelovige, een stuk hellevulsel.

Stellig zal hij hevige straffen lijden op de dag des oordeels! 
130 Sòë njang patéh nabi Moehamat - di akirat balaïh tjeuroega

Sinan nè ${ }^{s}$ mat meureuribèë — hankeu na mèë ta ${ }^{s}$ oepama

Sinan teumpat keudiaman - djidoee ${ }^{s}$ disinan rō $^{s} \mathrm{ro}^{s}$ masa

Dami neudeungò oelé nabi - oelat neutjòs lé sigra-sigra

Neupeudoeës ateuëh pha kiri - lòm neusoedi oelé sòjdina

$\mathrm{Na}$ kakeunaj kèë hé oelat - na tadapat ta di gata

Jōh njan oelat lòm djitalèh - lidah pasèh hana tara

Jōh njan oelat djipoedjòë nabi - oelōnteu toeri hé sòjdina Oelōnteu keunaj sit ka dilèë — gata pangoelèë sigala énsan Gata keusoedahan sigala nabi — gata ja sòjdi khajroe al-basari

140 Djakalèë hana gata sidròë - boeleuën ngòn oeròë han neupeuna

Hana araih ngòn koersi - hana nabi doem anbia

Djakalèë han gata ja Moehamat - malas ékat han neupeuna

Hana oeròë hana malam - alam sikeulian han neupeuna

Misé riwajat hadih Pidoesi - deungò saré doemna gata Khalaktoe alatjasa liadjeulika wakhalaktoeka liadjeuli

Njang koepeudjeuët doem peukara — sabab gata ka koepeuna

Koepeudjeuët gata keureuna dròë - Toehankoe sidròë njang koeasa Djakalèë han na gata lam nanggròë njòë - langèt ngòn boemòë

[han neupeuna

Djideungòkeu oelat poedjòë Moehamat - tahekeu $\mathrm{ra}^{\mathrm{s}}$ jat ban sineuna

150 Doeareutōih dròë jōh njan éseulam - Alah bri éleuham dalam dada

Beureukat mòsdjidat nabi Moehamat - oeba ${ }^{s}$ oelat neupeunjata

Pakala rasoelōlah salalahoe `alòjhé salam — ja doed mata koenta pi hadihi doerati kalat ad-doedatoe ja rasoelōlahi koentoe miat karan koeloe kareunoen seulasa wa seulasoena sanat Tanjòng nabi oeba ${ }^{s}$ oelat - padoemna tréb sinan gata Padoemna lama kateutapan - dalam intan tadoeës gata 
130 (Maar) wie gelooft in Nabi Muhammad, hem zal dat in het [hiernamaals met de hemel worden vergolden.

Daar zijn duizenderlei genietingen, waarvan men zich geen [voorstelling kan maken.

Dat is dan de standplaats, waar hij voor eeuwig zal verblijven." Met dat de profeet dat hoorde, nam hij de worm schielijk, Zette hem op zijn linker been, en ondervroeg hem:

„Kent ge mij o worm? kunt ge mij ook thuisbrengen?”

Toen gaf de worm alsnog bescheid, en zijn tong was weergaloos [goed versneden!

De worm loofde de profeet (en zei) : „Ik ken u Heer!

Ik ken $\mathrm{u}$ van oudsher, als hoofd van de ganse mensheid,

Gij zijt de laatste van de profeten, Gij o Heer zijt het beste van [alle vlees!

140 Waart Gij niet geweest, - God zou maan en zon niet hebben [geschapen!

Er zou geen troon zijn en geen zetel, en geen profeten zouden [hebben geprofeteerd.

Waart Gij niet geweest o Muhammad, God had de engelen niet [geschapen.

Er zou geen dag zijn en geen nacht, en alle werelden zou Hij niet [hebben doen zijn.

Luistert gij alleen naar wat door Firdazesi is overgeleverd:

Chalaktu '1-asjjāsa liadjlika wa chalaktuka liadjlī.

(d.i. : Dat ik schiep alle dingen, was om uwentwil, omdat ik u reeds

[had geschapen;

En u schiep ik om mijnentwil). De enige Here mijn is machtig!

Zo Gij niet waart van deze wereld, - hemel en aarde had $\mathrm{Hij}$

[niet geschapen!"

Horend hoe de worm Muhammad loofde, waren alle ras jat's stom

[verbaasd.

150 Tweehonderd man bekeerden zich toen tot de isläm, naar de

[ingeving die Allah hen deed ontvangen.

Door zijn zegen en bemiddeling deed nabi Muhammad bij de worm

[navraag:

Fakāla rasūlu '1-lāh șallā 'llāhu 'aleihi wasalām: Jā dūd mată kunta fì hazihi 'l-dūrati ḳălat ad-dūdatu ja rasulallāhi kuntu miat karn kullu karnun thalātha wa thalathuna sanat.

(d.i.: De profeet vroeg de worm: „Hoe lang hebt ge daar verbleven? Hoe lang zaat ge voor vast in die diamant?" 
Teuma djipeugah oelé oelat - tanjòng Moehamat sòjdén ambia Natadeungò ja djoendjōngan - karan sireutōïh sinan hamba Lhèëplöh-lhèë thōn sabòh karan — ja djoendjōngan tabitjara

160 Nabi Moehamat lòm neusarèh - peuë teuseubeh sinan gata Gata tadoeës dalam intan - tapoedjòë Toehan pakri batja

Meunòè teuseubèh lōn doeës $\operatorname{sinan}-$ ja djoendjōngan ngò lōn batja

Sōbeuhana man jarani wajaseumas oe kalami waja ${ }^{c}$ ripoeni

wa la jansani - tangò djeunòë lōn kheun masna

[wajadakoeni

Meuhasoetji pòkoe Toehan - baranggadjan hana loepa

Njang ngò soe lōn malam oeròë - lōn lam poedjòë rōs - rō $^{s}$ masa

Meuhasoetji pòkoe Toehan - lōn lam intan han tòm loepa Raseuki lōn doempeuë makanan — doempeuë keunan neupeuteuka

${ }^{\circ} \mathrm{Oh}$ djideungò soeara oelat - adjabkeu ra ${ }^{s}$ jat ban sineuna

170 Misé ka seuboet dalam koeroes an - tangòkeu toean lōn tjalitra Pakaloe ma hada'j-sihroe adjéb - hantòm ta ${ }^{5}$ eu wareuna roepa Meunan adjab doem geutanjòë - sabòh nanggròë ban sineuna Teuma djikheun oelé kaphé - Aboe Djahé njang tjilaka Ma hada'j-sihroe 'além

Meunankeu djikheun oelé kaphé - djikheun sihé njang that raja Teuma neuwòë nabi Moehamat - seureuta sahbat doem barang na Neuwòè landja oe Madinah - kakeu keumaïh lōn tjalitra Tamat hikajat kisah oelat - tjalitra sahbat oereuëng meulia

Aneus Abaïh sòjdina Abdōlah - njan njang kisah moela-moela 180 Dilèë kisah bahsa arab - lōn teureudjeumah ngòn bahsa kita

Njang teureudjeumah Abdōsalém - njang that ladém dalam dèësa Sinòë lōn seuboet mas na hadih — beutapatéh aj pangoelèë

Beuthat tameugaséh sabé énsan — tjarat djeunòë doe ${ }^{\circ}$ a talakèè

Tjoet ngòn rajeus rab ngòn djeus ōh - bès teudōh geunab watèè 
De worm zei op de vraag van Muhammad, de heer der profeten: „Wilt horen o geëerde! honderd eeuwen verbleef ik daar, En drieëndertig jaren is de duur van één eeuw, o geëerde, denk [eens aan!')

160 Nabi Muhammad informeerde nog: „Hoe was uw lofprijzing daar? Terwijl gij in de diamant verblijvend de Heer loofde, wat reciteerde [ge toen?"

„Aldus mijn lofprijzing terwijl ik daar zat, o geëerde, luister, ik [zal ze voor u lezen:

Subḥāna man jarānī wajasma ${ }^{\mathrm{c}} \mathrm{u}$ kalāmī waja ${ }^{\mathrm{c}}$ rifunī wajarzakunī wa lā jansāni Hoort nu dat ik u zegge wat dat betekent: „Opperreine, Here-mijn, God! nimmer, wanneer ook, zal ik u [vergeten!

Dat U mijn stem hoort, nacht en dag, komt doordat ik steeds doende [ben $\mathrm{U}$ te loven.

Opperreine, Here-mijn, God! U hebt mij in de steen nog nooit [vergeten!

Allerlei voedsel tot mijn levensonderhoud deedt Gij mij daar [toekomen!"

Vernemend de stem van de worm, verwonderden de ra ${ }^{\text {s }}$ jat's zich [allemaal.

$170 \mathrm{Zo}$ als in de koeran staat, - luistert heren, dat ik 't $\mathrm{u}$ vertelle:

Fakālū mā haẓā'l-sihru 'adjīb „Nog nooit zagen wij dingen

Van zo wonderlijk aanzien, wij allen, in het hele land!"

Maar de kafir $A b u$ Djahl, die ellendeling zei :

Mā hazā'l-sihru 'atlīm

Zó zei die kafir! Hij beweerde, dat 't een grote toverij was.

Nabi Muhammad ging daarop naar huis, tezamen met alle gezellen. Zij keerden huiswaarts naar Madinah. En daarmeê ben ik uitverteld. Uit is de hikajat met het verhaal van de worm, een vertelling,

[afkomstig van een edele gezel.

'Abbās' zoon : onze heer 'Abdullāh, - hij is 't, die ze 't eerst vertelde.

180 Oorspronkelijk was 't een arabische vertelling, maar ik vertaalde

[ze in ònze taal.

De vertaler is ${ }^{\circ}$ Abdulsālim, wien het zondigen zeer gewoon is.

Hier nu noem ik de zin van de overlevering; gelooft de verwanten

[van de profeet!

Gij mensen moet elkander wel zeer liefhebben! De voorwaarde nu

[is dat ge bidt!

Klein en groot, nabij en ver, - houdt daar geen ogenblik meê op! 
Dilèë pi teuma leubèh nibas njan - teungkoe sikeulian ateuëh oelèë Taleuëng djaròë doe ${ }^{c} a$ tabeuët - oeba $^{s}$ Toehan tameulakèë

Karangan njan sandja ${ }^{s}$ koereuëng — kòn ban oereuëng keumarang [dilèë

Lapaj pi singkat lagèè pi laban - lah sit toean koereuëng malèë

Bès peuë takheun teungkoe ampōn $-\operatorname{ta}^{s}$ eu djaròë lōn dis ateuëh [oelèë

190 Djakalèë salah bès tas oepat lé - beusabéh piké bitjara dilèë

Meunankeu tjarat tameutjèëdara - misé haba oereuëng dilèë

Amin ja Rabōnalamin - Toehan peukeunan njang talakèë

Peuë njang pinta Pòteu neubri - beu soenggōh até tameulakèë

Beureukat mòdjidat nabi Moehamat — peuë njang hadjat boe [meuteumèë Peuë njang pinta pi Toehan bri - beureukat wali doedòë ngòn dilèë Ngòn beureukat Makah Madinah - éntja Alah beureukat goerèë Beuna ampōn abi bapa - toeha moeda waréh sampèè

$\mathrm{La}^{\text {sén niba }}{ }^{\mathrm{s}}$ njan rakan sahbat - hingga oemat nabi dilèë Njang joeë soerat Sajét Édeuréh — kawōm tjaréh aj pangoelèë

200 Lagi gasiën ngòn meuseukin - aneu ${ }^{s}$ jatim koereuëng èleumèë Bès takhém-khém teungkoe ampōn - ta $^{s}$ eu djaròë lōn ateuëh oelèë Lōn tamsé boengòng reutòs ${ }^{s}$ tamsé poenggoe ${ }^{s}$ boeleuën peulagèë Até lōn bitjah lōn dòng lōn doeës - tamsé reujeuës bitjah ba ${ }^{s}$ batèë

Lōn oepama boengòng kala - salah nama djheut ngòn bèè $\mathrm{Ba}^{s} \mathrm{dji}$ sangat boengòng sangat - han moepakat tamsé kajèè 
Vroeger werd er méér gebeden. Gij allen teungkoe's, boven het hoofd Moet ge spreiden uw handen en bidden uw gebeden! Tot God [moet ge richten uw gebed.

Dit gedicht schiet te kort op het punt van de maat. 't Is niet zo als [de mensen vroeger dichtten.

De woorden zijn te kort, de wijze is te vrij, 't mankeert mij aan [een passend gevoel van schaamte.

Zegt er maar niets van teungkoe's, ziet, mijn handen houd ik al [boven mijn hoofd.

190 Waar ik verkeerd deed, duidt 't mij niet ten kwade! Wilt eerst [wel alles in aanmerking nemen!

Zo zijn de vereisten om zich te kunnen verbroederen, naar het [zeggen van de ouden.

Amen, o Heer van de werelden! De Heer geeft dat waar wij om [smeken!

Wat wij verzoeken, God staat 't ons toe! maar dan moeten wij [daar ijverig om bidden!

Door de zegen en de voorspraak van nabi Muhammad mogen dan [de hartewensen vervuld worden!

Wat ge smeekt, God geeft 't, door de zegen van de heiligen van [later en vroeger.

Door de zegen van Makah en Madinah en, zo God 't wil, door de [zegen van mijn leraar,

Moge mij vergeven worden door vader en door mijn neven, oud [en jong, en mijn verwanten van vaders- en van moederszij! Voorts door de makkers en vrienden, tot en met de gemeenteleden [van de profeet vroeger.

Sajjid Idris, een nazaat uit de familie van de profeet, was 't, die [mij aan het schrijven zette.

200 Waar ik arm ben en behoeftig en een wees van ontoereikende [wetenschap,

Moet ge mij niet uitlachen, hoge heren! Ziet, mijn handen houd [ik boven mijn hoofd.

Ik ben als een zieke bloem; of als de in de maan verliefde nachtuil, [waarmee door de aangebedene een wreed spel wordt gespeeld. Of ik ga of sta, mijn hart pijnt als gewond, als aan stukken, [gelijk de golf, welke breekt op de rots.

Ik ben als een kala-bloem: de naam is lelijk, de reuk is kwalijk, De stengel is erg, de bloem is erg; die dingen zijn niet in onderlinge [harmonie zo als dat anders bij een boom 't geval is (?) 
Di kajèë na djimoepakat - sipreuti adat doedòë ngòn dilèë

Lōn oepama daroeët tjoemoeët - han sakòn djeuët [djeungkaj-meungkaj

Keumeung geumoelam hana bahō - keumeung seumeus ōn han

Karangan njòë sandjas koereuëng — han ban oereuëng keumarang [gèt lagèè [dilèë

210 Njang joeë soerat Sajét Édeuréh - oelōnteu soerat neukheun [areutòë

Walahoe a lamoe bilșawābi - deungòn teubaj that Alah njang thèë Walah al-hadi ali sabi al-Rasjad - djalan njang teupat Alah Amin ja Rabōn alamin — kaboej mòsmin lakèë doe ${ }^{c} a$ [peuteuntèë $\mathrm{T}$ a m a t 
Bij een boom toch pleegt alles van één karakter te zijn, gelijk de [adat van later in overeenstemming is met die van vroeger.

Ik ben als een etterkrekel (?), tot niets nut, onhebbelijk en [onvoldragen.

Ik wil mijn vrachtje op de schouder nemen maar heb geen schouders; [ik wil 't op het hoofd nemen, maar - dat staat niet!

Dit gedicht is gebrekkig op het punt van de maat; 't is niet als wat [men vroeger dichtte!

210 Sajiid Idris was 't die mij zei te schrijven; en ik schreef, en hij [zei wàt ik moest schrijven.

God weet ten volle wàt de waarheid is!

Allah is de wegwijzer op de weg der godgeleerden. Wat de rechte [weg is, God stelde dat vast.

Amen! o Heer der werelden, sta toe wat Uw gemeenteleden $U$ bidden! Einde. 